\title{
Attitudes towards bipolar disorder and predictive genetic testing among patients and providers
}

\author{
Lauren B Smith, Benjamin Sapers, Victor I Reus, Nelson B Freimer
}

\begin{abstract}
Attitudes about bipolar disorder (manic depressive disorder) and genetic testing were investigated. Three groups of subjects were surveyed including members of a manic depressive support group, medical students, and psychiatry residents. The questionnaire was intended to elicit impressions and attitudes about bipolar disorder (BP) from mental health consumers and health care providers with varying levels of personal and professional familiarity with the disorder. Attitudes towards prenatal testing and pregnancy termination were also assessed.

The intention hypothetically to terminate a pregnancy was influenced by the likelihood of developing BP as well as the projected course and severity of illness. Nearly half of the total sample would terminate pregnancy if the fetus were definitely to develop an unspecified form of bipolar disorder. Presumed severity of illness was also found to be a modifying factor in the decision, with a low percentage of subjects electing to terminate for a mild course of bipolar disorder and a majority opting for termination in the case of an extremely severe presentation.

Support group members were the least likely to terminate a hypothetical pregnancy in the case of a positive prenatal test and were the most likely to desire childhood testing in the absence of preventive or treatment options. The possible implications of these findings, as well as avenues of future research, are discussed. (f Med Genet 1996;33:544-549)
\end{abstract}

Center for

Neurobiology and

Psychiatry and

Neurogenetics

Laboratory,

Lepartment of

Department of
Psychiatry, University

of California at

San Francisco, USA

L B Smith

B Sapers

V I Reus

N B Freimer

Correspondence to:

Dr Freimer, Neurogenetics

Laboratory, Langley Porter

Psychiatric Institute, UCSF,

San Francisco, CA 941430984, USA.

Received 28 November 1995

Revised version

accepted for publication

16 February 1996 the impact of testing for rare genetic disorders, additional issues arise with complex, common diseases. Recent attention has focused on breast and colon cancer, but presymptomatic testing may also soon be feasible for psychiatric disorders, in particular for bipolar disorder (BP). In this paper we present the findings of our preliminary efforts to investigate attitudes and experiences of people familiar with $\mathrm{BP}$, and relate these to the eventual implementation of genetic testing.

Prenatal testing was initially developed for disorders in which a biochemical or gross chromosomal abnormality could be detected. The mapping of single gene mendelian disorders expanded prenatal screening and permitted testing of presymptomatic subjects. With the recent cloning of genes and the characterisation of mutations for common diseases, testing will soon be available for a significantly larger proportion of the population. A substantial percentage of the general public reports an interest in genetic testing for colon cancer ${ }^{1}$ and there is also a high potential demand for genetic testing in response to recently identified mutations involved in breast and ovarian cancers (for example, in the BRCAl gene). ${ }^{2}$

A number of studies have examined the attitudes toward genetic testing of people who have participated in currently available genetic counselling and testing programmes. People at risk for Huntington's disease, neurofibromatosis, Duchenne muscular dystrophy, and breast/ovarian cancer have been studied in this regard..$^{2-5}$ As the number of diseases amenable for testing increases, additional ethical, legal, and psychological issues will arise. In particular, factors that may be specific to psychiatric disorders have been insufficiently explored.

Family, twin, and adoption studies have supported the genetic heritability of bipolar disorder. ${ }^{6}$ More significantly, a well designed twin study found a concordance rate for BP in monozygotic twins that was more than twice the rate observed in dizygotic twins. ${ }^{7}$ The evidence for the heritability of bipolar disorder is stronger than that for other psychiatric illness, including unipolar depression and schizophrenia. Research in molecular genetics supports epidemiological data. Recent studies suggest that one or more BP loci have already been genetically mapped; therefore mutations responsible for BP susceptibility may soon be identified. ${ }^{89}$

We assessed the attitudes of members of a national BP support group, medical students, and psychiatry residents regarding the impact of BP on people and their families, the efficacy of available treatments for BP, the circumstances in which termination of pregnancy 
Table 1 Demographics

\begin{tabular}{|c|c|c|c|c|c|c|c|c|}
\hline & \multicolumn{2}{|c|}{ Total } & \multicolumn{2}{|c|}{ Support group } & \multicolumn{2}{|c|}{ Medical students } & \multicolumn{2}{|c|}{ Residents } \\
\hline & No & $\%$ & No & $\%$ & No & $\%$ & No & $\%$ \\
\hline Male & 48 & 52 & 20 & 47 & 19 & 61 & 9 & 47 \\
\hline Female & 45 & 48 & 23 & 53 & 12 & 39 & 10 & 53 \\
\hline \multicolumn{9}{|l|}{ Age } \\
\hline $18-29$ & 48 & 43 & 7 & 15 & 33 & 93 & 8 & 27 \\
\hline $30-39$ & $\begin{array}{l}40 \\
34\end{array}$ & 30 & 12 & 26 & 2 & 7 & 20 & 67 \\
\hline $40-49$ & 16 & 14 & 14 & 30 & & & 2 & 6 \\
\hline $50+$ & 14 & 13 & 14 & 30 & & & & \\
\hline \multicolumn{9}{|l|}{ Marital status } \\
\hline Single & 76 & 68 & 23 & 49 & 30 & 86 & 23 & 77 \\
\hline Married & 22 & 20 & 12 & 26 & 4 & 11 & 6 & 20 \\
\hline Separated & 5 & 5 & 5 & 11 & 0 & 0 & 0 & 0 \\
\hline Divorced & 9 & 8 & 7 & 15 & 1 & 3 & 1 & 3 \\
\hline \multicolumn{9}{|l|}{ Education } \\
\hline High school graduate & & & 1 & 2 & & & & \\
\hline Some college & & & 13 & 28 & & & & \\
\hline College degree & & & 13 & 28 & & & & \\
\hline Some graduate school & & & 8 & 17 & 35 & 100 & & \\
\hline Graduate degree & & & 12 & 26 & & & 30 & 100 \\
\hline \multicolumn{9}{|l|}{ Religiosity } \\
\hline Not & 45 & 40 & 17 & 36 & 9 & 26 & 19 & 63 \\
\hline Somewhat & 33 & 30 & 14 & 30 & 13 & 37 & 6 & 20 \\
\hline Moderate & 23 & 21 & 11 & 23 & 8 & 23 & 4 & 13 \\
\hline Very & 11 & 10 & 5 & 11 & 5 & 14 & 1 & 3 \\
\hline
\end{tabular}

Table 2 Psychiatric history

\begin{tabular}{|c|c|c|c|c|c|c|c|c|}
\hline & \multicolumn{2}{|c|}{ Total } & \multicolumn{2}{|c|}{ Support group } & \multicolumn{2}{|c|}{ Medical students } & \multicolumn{2}{|c|}{ Residents } \\
\hline & No & $\%$ & No & $\%$ & No & $\%$ & No & $\%$ \\
\hline \multicolumn{9}{|l|}{ Consultation } \\
\hline Personal & 76 & 67 & 44 & 92 & 10 & 29 & 22 & 73 \\
\hline Family member & 77 & 70 & 36 & 80 & 16 & 46 & 25 & 83 \\
\hline \multicolumn{9}{|l|}{ Medication } \\
\hline Personal & 44 & 40 & 35 & 76 & 4 & 11 & 5 & 18 \\
\hline Family member & 55 & 52 & 30 & 71 & 7 & 21 & 18 & 62 \\
\hline \multicolumn{9}{|l|}{ Hospitalisation } \\
\hline Personal & 29 & 26 & 27 & 60 & 0 & & 2 & 7 \\
\hline Family member & 36 & 32 & 22 & 51 & 6 & 17 & 7 & 23 \\
\hline
\end{tabular}

might be considered, and the likely repercussions of genetic testing with respect to confidentiality. While previous investigations have assessed the psychological dimensions of BP, the current study aimed to build upon this research and specifically examine attitudes that may be pertinent to the development of genetic testing. ${ }^{10}$ Other studies have also reported that health care providers have different views of genetic testing than do their patients, and such discrepancies may result in a misunderstanding of patients' intentions and priorities. ${ }^{112}$ The responses of health care providers may differ depending upon their level of training. This survey was undertaken to examine the implications of genetic testing for bipolar disorder in a population familiar with the disease.

\section{Methods}

An anonymous, self-report questionnaire was developed to investigate attitudes about BP. It was designed to be used for subjects who had a high school education but who were not health professionals or scientists. The survey included an assessment of personal and family psychiatric history, perceptions of functional impairment, and evaluations of treatment efficacy. It also elicited attitudes towards predictive testing, pregnancy termination, and confidentiality.

Questionnaires were distributed to 185 people and $113(61 \%)$ surveys were completed. The response rate was $48 / 55(87 \%)$ of the members of the support group, $35 / 65(54 \%)$ of the medical students, and $30 / 65(46 \%)$ of the residents.

Members of the support group were recruited at a local meeting. This organisation included affected subjects, partners, friends, and relatives. Subjects filled out the questionnaire anonymously and returned it after the meeting or by mail. This group was chosen to represent the population potentially most affected by future genetic testing for BP. We chose to include affected subjects as well as their family members and friends to encourage participation and ensure confidentiality.

Medical students and psychiatry residents were surveyed in order to assess the attitudes of health care providers at different stages of training. Second year medical students were sampled and participants returned the survey in a stamped envelope. Psychiatry residents returned the questionnaire by campus mail.

As this was an exploratory study, formal analyses were not conducted. This investigation was intended to uncover issues, formulate hypotheses, and provide a direction for future research; therefore, descriptive statistics are presented.

\section{Results}

DEMOGRAPHICS

Characteristics of the study population are shown in table 1 . Of particular note, the educational level was high in the support group with $43 \%$ having at least some graduate education. The medical students were the most religious group, followed closely by the support group. The residents reported the lowest levels of religiosity.

\section{EXPERIENCE WITH BP}

Table 2 provides the data for experience with psychiatric consultation, medication, and hospitalisation. It also indicates the number of respondents who have family members or friends with a psychiatric history.

Our sample of support group members was primarily composed of mental health consumers. Over three-quarters had either taken psychiatric medication or been hospitalised, respresenting substantive psychiatric experience; $92 \%$ have personally consulted a psychiatrist. Therefore, very few members of the support group have no personal psychiatric experience. The responses of the "patients" and the smaller subset of "supporters" are comparable on all of the variables of interest in this investigation; therefore, they are treated as a single group.

On perceptions of how much BP interferes with various aspects of life, including career plans and relationships, the support group members, medical students, and residents are similar (table 3 ). BP is rated as interfering at least moderately (on a five point scale with $1=$ not at all and $5=$ severely) for all of the experiences studied (marriage, children, goals, career, education, and finances). On average, it is rated as interfering the most with marriage (relationships) (3.9) and raising children (3.7) 
Table 3 The impact (mean) of BP on life experience $(1=$ not at all, $3=$ moderate, $5=$ severe)

\begin{tabular}{lllll}
\hline & Total & Support group & Medical students & Residents \\
\hline Marriage (relationships) & $3 \cdot 9$ & $3 \cdot 8$ & $3 \cdot 9$ & $3 \cdot 8$ \\
Raising children & $3 \cdot 7$ & $3 \cdot 8$ & $3 \cdot 9$ & $3 \cdot 8$ \\
Aspirations or goals & $3 \cdot 6$ & $3 \cdot 7$ & $3 \cdot 4$ & $3 \cdot 5$ \\
Career & $3 \cdot 6$ & $3 \cdot 7$ & $3 \cdot 5$ & $3 \cdot 4$ \\
Education & $3 \cdot 1$ & $3 \cdot 0$ & $3 \cdot 1$ & $3 \cdot 2$ \\
Finances & 3.6 & $3 \cdot 6$ & $3 \cdot 3$ & $3 \cdot 8$ \\
\hline
\end{tabular}

and the least in terms of educational attainment $(3 \cdot 1)$. Members of the support group, on average, rated $\mathrm{BP}$ as more stigmatising than did the other respondents (on a five point scale) with $68 \%$ of them rating a diagnosis of BP as highly stigmatising compared to $47 \%$ of residents and $62 \%$ of medical students.



Figure 1 The hypothetical intention to terminate a pregnancy among the three groups of subjects if the fetus would have a - \% risk of developing bipolar disorder.

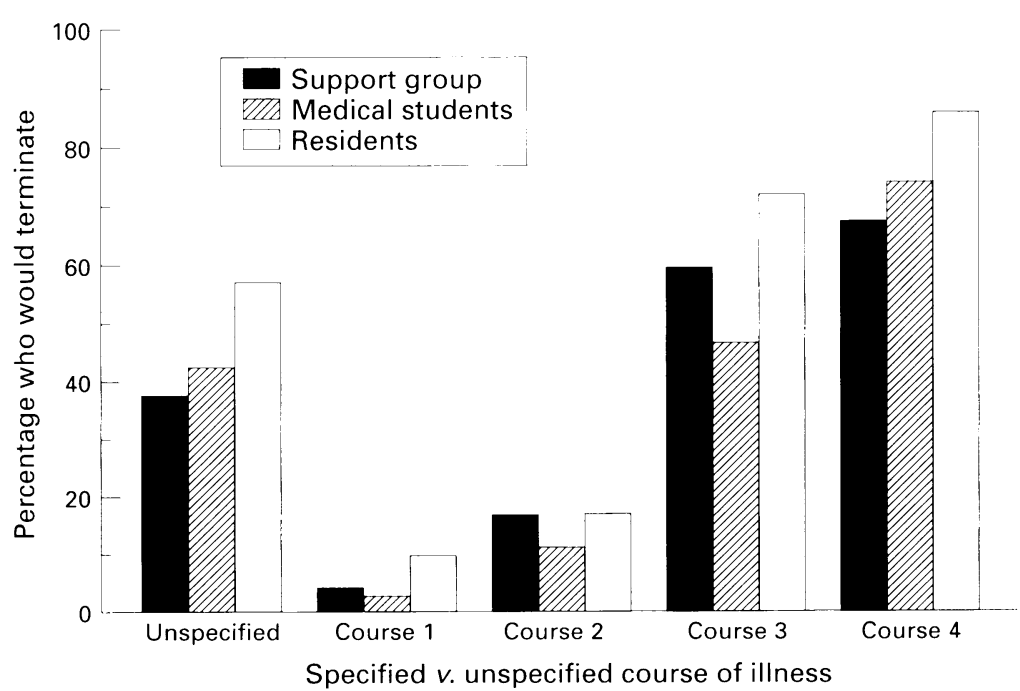

Figure 2 A comparison of the hypothetical intention to terminate a pregnancy for unspecified and specified courses of illness. Course $1=1$ episode of mania and depression, no hospitalisations, no recurrence. Course 2 $2-3$ episodes of mania and depression, 1-2 hospitalisations. Course $3=>5$ episodes, hospitalisation necessarv $25 \%$ of lifetime, suicide risk. Course $4=$ severe suicide risk, hospitalisation necessary at least $50 \%$ of lifetime.
TERMINATION OF PREGNANCY

The observed trends indicate that the decision to terminate a pregnancy may be influenced by the likelihood of developing BP as well as the anticipated course of illness. The degree to which people state that they would be likely to terminate a pregnancy is positively correlated with the fetus's risk of developing BP (fig 1). Willingness to terminate a pregnancy also varies with the clinical manifestations of BP. For example, when respondents were presented with multiple clinical scenarios their responses varied substantially. Respondents indicated a low intention to terminate a pregnancy $(5 \%)$ when presented with the likelihood that the child would experience a mild course of illness (one episode of mania and one episode of depression). However, the description of a severe clinical scenario (severe suicide risk, $50 \%$ of lifetime hospitalised) dramatically increased the hypothetical rate of pregnancy termination $(75 \%)$. Fig 2 shows the differences between the responses for an unspecified course of BP and the responses for each level of severity. In comparing groups, there is some variation in the intention to terminate pregnancy under each condition. The residents report the highest intention to terminate pregnancy for each clinical scenario of BP.

A higher proportion of total respondents $(82 \%)$ indicated that they would terminate pregnancy for another life threatening or severely debilitating disorder. The residents were the most likely to terminate pregnancy for another serious disease $(96 \%)$ in comparison to medical students $(78 \%)$ and members of the support group $(76 \%)$.

PRESYMPTOMATIC TESTING

All of the groups expressed a high level of interest in testing children if prophylactic drug treatments were available (fig 3);89\% of the subjects would have their children undergo testing. The intention to test with available treatment is very similar in all of the groups, with $83 \%$ of the support group members, $97 \%$ of the medical students, and $89 \%$ of the residents opting for testing.

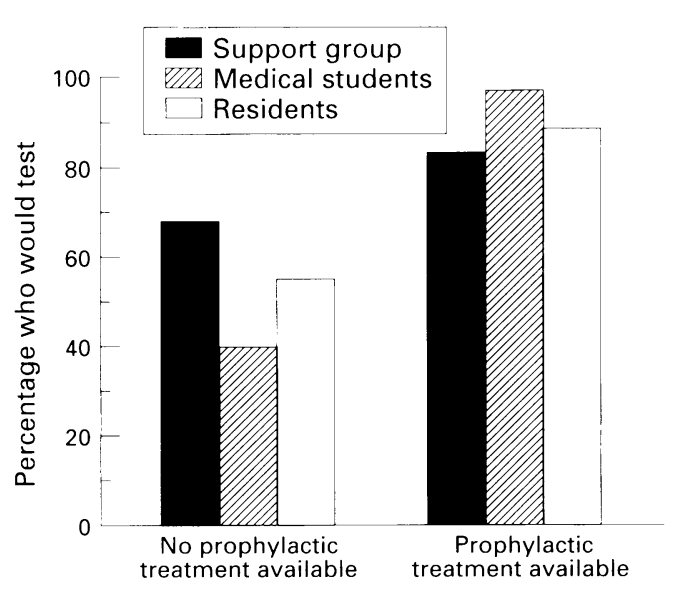

Figure 3 The intention to have children tested for bipolar disorder with and without prophylactic treatment options. 

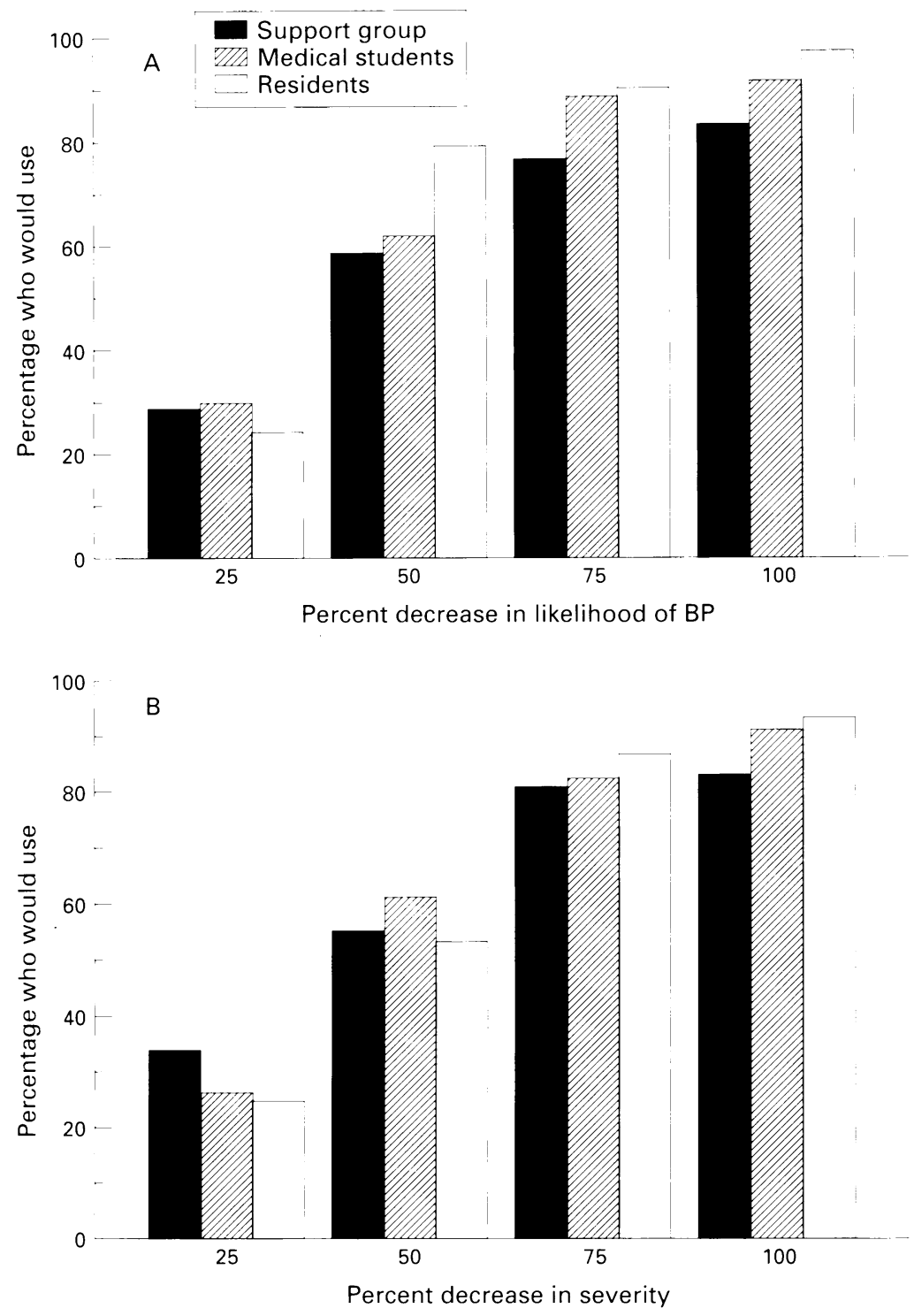

Figure 4 (A) The hypothetical use of prophylactic drug treatment to reduce the likelihood of developing bipolar disorder. (B) The hypothetical use of prophylactic drug treatment to reduce the severity of bipolar disorder.

Without available treatment, $56 \%$ of the respondents would have their children tested. Support group members were the most interested in testing in the absence of treatment options $(68 \%)$.

\section{PROPHYLACTIC TREATMENT}

In order to assess attitudes toward prophylactic treatment, it is informative to investigate attitudes toward current pharmacological treatment of BP. Psychiatry residents and medical students rate lithium as slightly more effective with fewer side effects than do the support group members, but this difference is minimal (table 4). Nearly one fifth of the support group

Table 4 Perception of the current standard of treatment

\begin{tabular}{lllll}
\hline & Total & Support group & Medical students & Residents \\
\hline Lithium efficacy & $4 \cdot 4$ & $4 \cdot 0$ & $4 \cdot 6$ & $4 \cdot 8$ \\
$\begin{array}{l}(1=\text { not helpful, } 5=\text { very helpful) } \\
\text { Lithium side effects }\end{array}$ & $2 \cdot 6$ & $2 \cdot 8$ & $2 \cdot 6$ & $2 \cdot 5$ \\
$(1=$ not impairing, 5= severely impairing) & & & \\
\hline
\end{tabular}

members and medical students stated that they are unable to rate its efficacy.

Attitudes about prophylactic drug treatment for susceptibility to BP were also assessed (fig 4). A high proportion of all three groups would take a drug prophylactically to decrease the likelihood of developing BP or to decrease the severity of BP.

\section{Discussion}

The results of this investigation, although preliminary, identify several of the issues likely to emerge in genetic testing for psychiatric disorders. In the absence of statistical tests, these data represent trends and the conclusions are tentative. They are presented to suggest areas of future research.

It is clear that there is a high hypothetical demand for genetic testing among all groups studied, even in the absence of preventive treatment options. These results also suggest that there are additional variables that deserve consideration when counselling people who are considering prenatal or presymptomatic testing for common diseases in comparison with rare, inherited disorders.

$\mathrm{BP}$ is characterised by a variable course; this fact is central to considering how genetic testing may be implemented for this disorder. For example, in this study, the hypothetical decision to abort an affected child is dependent upon the course of illness. Even though BP has a defined set of diagnostic criteria, the presentation of the illness can vary substantially. While some patients may meet the criteria for a manic episode once in their life time, others may experience several episodes requiring multiple hospitalisations. Some patients may become psychotic during episodes and others may not. Unlike BP, many of the disorders for which testing is currently available have a fairly predictable course and high penetrance. For example, Huntington's disease may have a variable age of onset but it is clear that the course is debilitating and ultimately fatal. Many people undergo genetic testing to end the uncertainty in their lives ${ }^{1314}$; this resolution, however, may not be possible for those at high risk for BP since genetic testing does not provide information about the severity of illness. This fact could also have consequences for couples who desire prenatal testing for BP. In testing for other disorders, it has been found that an uninformative result can be the most stressful outcome of diagnostic testing and can continue to cause distress for parents during the child's subsequent development. ${ }^{15}$ This may be an issue in prenatal testing for BP if the test is positive but the severity remains unknown.

Genetic counsellors will not be able to predict the course of BP for their clients but they can attempt to convey the fact that it is highly variable. If the variability is not understood, it is possible that people could base their impression of the illness on one familiar case and assume that this is the typical course. While counsellors can attempt to assess personal reasons for testing and provide information about the disorder, this may not be sufficient 
to clarify the results of a positive test. Studies have found that counselling is viewed positively by the people who are being tested, ${ }^{516}$ but the retention of this knowledge is very low in some studies. ${ }^{51718}$ It has also been shown that the concept of genetic risk is difficult to comprehend and interpret. ${ }^{19}$ Subjects who have been counselled often exaggerate or minimise their risk in an attempt to use it as a guideline for reproductive behaviour. ${ }^{12}$ Such people apparently seek a sense of certainty, whether real or distorted. Since testing for BP will involve inherent uncertainty, interpretation of the results of genetic testing is likely to be based on highly individualised cognitive strategies.

The variability and incomplete penetrance of $\mathrm{BP}$, however, may provide opportunities for prevention following presymptomatic testing. It is possible that preventive psychotherapy or the modification of specific risk factors could avert the onset of $\mathrm{BP}$, although the nature of these interventions has yet to be established. In our sample, deciding whether to use a hypothetical prophylactic treatment varies with the severity and likelihood of BP; therefore, the decision to use prophylactic medication is likely to involve a careful evaluation of efficacy, side effects, and convenience. Prevention and treatment will continue to be factors in the debate over genetic testing as more options are developed and other genes for complex diseases are cloned.

The trends in our data suggest that the respondents are not ambivalent about terminating pregnancies for genetic disorders, but instead are sensitive to the complexities of psychiatric illness. All three groups would be more likely to terminate a pregnancy for other highly debilitating or life threatening disorders than for BP, even when considering the most severe course of illness. If an extremely severe form of $\mathrm{BP}$ is presented, the percentage of respondents who would terminate pregnancy increases to high levels but is still lower than for other serious disease. This may be because though $\mathrm{BP}$ can be extremely severe, it is not generally fatal. Mental debilitation may also be viewed differently from physical disability. The ethics of prenatal genetic testing for a condition that is not life threatening have been debated and will continue to be an issue as genes are identified for other conditions that affect a person's "quality of life".

Similar controversy surrounds the issue of childhood testing. ${ }^{20}$ Members of the support group are the most likely to desire childhood testing in the absence of treatment, and are the least likely hypothetically to abort an affected fetus. If prenatal testing occurs in the absence of termination, parents would know that a child was susceptible to a disorder that, in the case of BP, may not develop until adulthood. This presymptomatic knowledge could influence the child's early environment and opportunities and may result in discrimination and stigma. ${ }^{21}$ Many parents believe that it would be valuable to know if their child will be affected even if they intend to continue the pregnancy; however, it is unclear whether it is the parent's or the child's right to obtain this information. Preliminary guidelines have been suggested but they have not been adopted as national standards. ${ }^{2122}$ It is interesting that members of the support group are apparently more willing than are the providers to test children, despite the fact that they give BP higher ratings of stigma. This discrepancy may reflect the anticipation of advantages of testing for the child other than treatment or indicate a desire to resolve uncertainty. Once testing is available it will be important to reassess the actual rates of use since it has also been shown that the hypothetical demand for prenatal and presymptomatic screening is greater than actual testing rates. ${ }^{23-25}$ Careful consideration of the issues over time may allow respondents to weigh all of the implications of their decisions.

Treatment options do not appear to influence the low intention to terminate after prenatal testing since the lithium ratings of the members of the support group are comparable to those of the other subjects. The fact that support group members rate $\mathrm{BP}$ as more stigmatising than do medical students and residents is an example of the different perspectives of consumers and providers. Differences in attitudes can have an impact on counselling, as was found in a study of subjects counselled for Down syndrome in which subjects complained of physician bias against continuing pregnancies or future childbearing. ${ }^{26}$

Additional research is needed to investigate these preliminary trends and observations. It will be necessary to clarify the psychological impact of testing for psychiatric disorders and explore the efficacy of premorbid interventions in altering the course and severity of illness. It would also be informative to survey the general public on their attitudes about psychiatric illness, since people unfamiliar with specific diseases may also have the option of genetic testing, particularly for disorders as common as BP. While the decision to undergo genetic testing for BP will undoubtedly involve many personal and legal considerations, it should be possible to delineate the primary issues and form policy recommendations before the implementation of testing.

This research was supported by grants from the National Institute of Health (MH 00916 and MH 49499). We would like to acknowledge Susan Service, Laura Bull, Alison McInnes, Carol Mathews, Nancy Adler, Victoria Carlton, Michael Escamilla, and the reviewers for helpful comments on the manuscript.

1 Croyle RT, Lerman C. Interest in genetic testing for colon cancer susceptibility: cognitive and emotional correlates. Prev Med 1993;22:284-92.

2 Lerman C, Daly M, Masny A, et al. Attitudes about genetic testing for breast-ovarian cancer susceptibility. $\mathcal{F}$ Clin Oncol 1994;12:843-50.

3 Kessler S, Field T, Worth L, et al. Attitudes of persons at risk for Huntington disease toward predictive testing. $\mathrm{Am}$ f Med Genet 1987;26:259-70.

4 Fed Genet 1987;26:259-70. type 1 (NF1): knowledge, experience, and reproductive type 1 (NF1): knowledge, experience, and reproductive decisions of affect

5 Rona RJ, Beech R, Mandalia S, et al. The influence of genetic counselling in the era of DNA testing on knowledge, counselling in the era of DNA testing on knowledge, reproductive intentions

6 Goodwin FK, Jamison KR Manic-depressive illness. New York: Oxford University Press, 1990.

7 Bertelsen A, Harvald B, Hauge M. A Danish twin study of manic-depressive disorders. Br f Psychiatry 1977;130: 330-51

.


8 Berrettini WH, Ferraro TN, Goldin LR, et al. Chromosome 18 DNA markers and manic-depressive illness: evidence for a susceptibility gene. Proc Natl Acad Sci USA 1994; 91:5918-21.

9 Freimer NB, Reus VI, Escamilla ME, et al. Genetic mapping using haplotype, association and linkage methods suggests a locus for severe bipolar disorder (BPI) at 18q22-23. Nature Genet 1996;12:436-41.

10 Targum SD, Dibble ED, Davenport YB, et al. The family attitudes questionnaire: patients' and spouses' views of bipolar illness. Arch Gen Psychiatry 1981;38:562-8.

11 Thies U, Bockel B, Bochdalofsky V. Attitudes of neurologists, psychiatrists, and psychotherapists towards predictive testing for Huntington's disease in Germany. $\mathcal{f}$ Med Genet 1993;30:1023-7.

12 Parsons EP, Clarke AJ. Genetic risk: women's understanding of carrier risks in Duchenne muscular dystrophy. $\mathcal{f} \mathrm{Med}$ Genet 1993;30:562-6.

13 Evers-Kiebooms G, Swerts A, Cassiman JJ, et al. The motivation of at-risk individuals and their partners in deciding for or against predictive testing for Huntington's disease. for or against predictive testing
Clin Genet 1989;35:29-40.

14 Bloch $M$, Fahy M, Fox S, et al. Predictive testing for Huntington disease. II. Demographic characteristics, life style patterns, attitudes, and psychosocial assessments of the first fifty-one candidates. Am $\mathcal{f}$ Med Genet 1989;32: 217-24.

15 Adler NE, Keyes S, Robertson P. Psychological issues in new reproductive technologies: pregnancy-inducing technology and diagnostic screening. In: Rodin J, Collins
$\mathrm{A}$, eds. Women and new reproductive technologies: medical, psychosocial, legal, and ethical dilemmas. Hillsdale NJ: Lawrence Erlbaum, 1991.
16 Mitchell J, Scriver CR, Clow CL, et al. What young people think and do when the option for cystic fibrosis carrier testing is available. f Med Genet 1993;30:538-42.

17 Bekker H, Denniss G, Modell M, et al. The impact of population based screening for carriers of cystic fibrosis. f Med Genet 1994;31:364-8.

18 Levy M, Pirson Y, Simon P, et al. Evaluation in patients with Alport syndrome of knowledge of the disease and attitudes toward prenatal diagnosis. Clin Nephrol 1994;42: 211-20.

19 Green J, Murton F, Statham H. Psychological issues raised by a familial ovarian cancer register. $\mathcal{F}$ Med Genet 1993;

20 Marshall E. A tough line on genetic screening. Science 1993; 262:984-5

21 Wertz DC, Fanos JH, Reilly PR. Genetic testing in children and adolescents: who decides? $\mathcal{F} A M A$ 1994;272:875-81.

22 New York Times. Should children know of disease risk? Debate rages over genetic knowledge. The San Francisco Chronicle, 27 September 1994

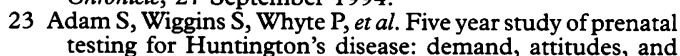
psychological assessment. $\mathcal{F}$ Med Genet 1993;30:549-56.

24 Quaid KA, Morris M. Reluctance to undergo predictive testing: the case of Huntington disease. Am $\mathcal{F}$ Med Genet 1993;45:41-5.

25 Decruyenaere $M$, Evers-Kiebooms G, Van den Berghe $H$. Perception of predictive testing for Huntington's disease by young women: preferring uncertainty to certainty? $\mathcal{F}$

26 Elkins TE, Stovall TG, Wilroy S, et al. Attitudes of mothers of children with Down syndrome concerning amniocentesis, abortion, and prenatal genetic counseling techniques. Obstet Gynecol 1986;68:181-4. 